
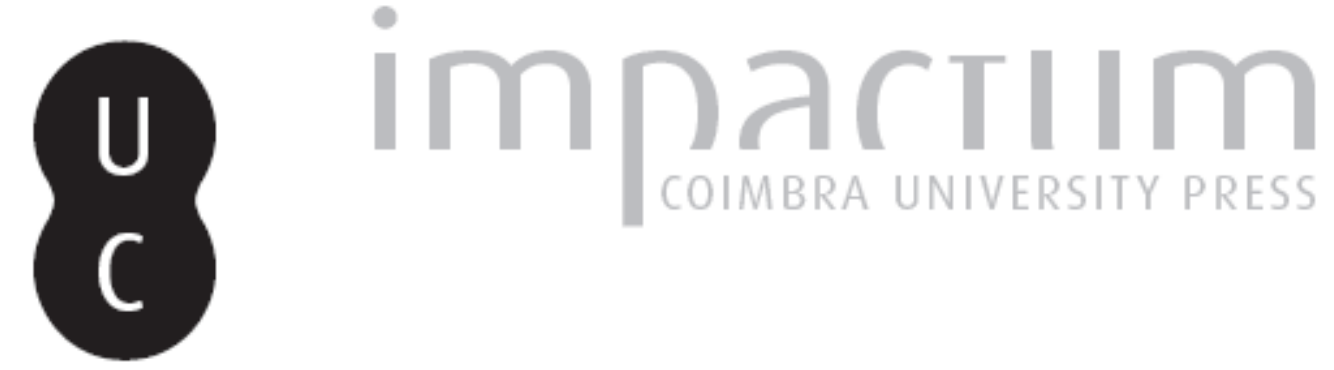

\title{
[Recensão a] MARIO REGALI (2012), Il poeta e il demiurgo. Teoria e prassi della produzione letteraria nel Timeo e nel Crizia di Platone
}

Autor(es): $\quad$ Langone, Hugo

Publicado por: Centro de História da Universidade de Lisboa

URL

persistente:

URI:http://hdl.handle.net/10316.2/38935

DOI:

DOI:http://dx.doi.org/10.14195/0871-9527_24_11

Accessed : $\quad$ 26-Apr-2023 07:26:29

A navegação consulta e descarregamento dos títulos inseridos nas Bibliotecas Digitais UC Digitalis, UC Pombalina e UC Impactum, pressupõem a aceitação plena e sem reservas dos Termos e Condições de Uso destas Bibliotecas Digitais, disponíveis em https://digitalis.uc.pt/pt-pt/termos.

Conforme exposto nos referidos Termos e Condições de Uso, o descarregamento de títulos de acesso restrito requer uma licença válida de autorização devendo o utilizador aceder ao(s) documento(s) a partir de um endereço de IP da instituição detentora da supramencionada licença.

Ao utilizador é apenas permitido o descarregamento para uso pessoal, pelo que o emprego do(s) título(s) descarregado(s) para outro fim, designadamente comercial, carece de autorização do respetivo autor ou editor da obra.

Na medida em que todas as obras da UC Digitalis se encontram protegidas pelo Código do Direito de Autor e Direitos Conexos e demais legislação aplicável, toda a cópia, parcial ou total, deste documento, nos casos em que é legalmente admitida, deverá conter ou fazer-se acompanhar por este aviso.

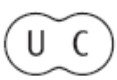




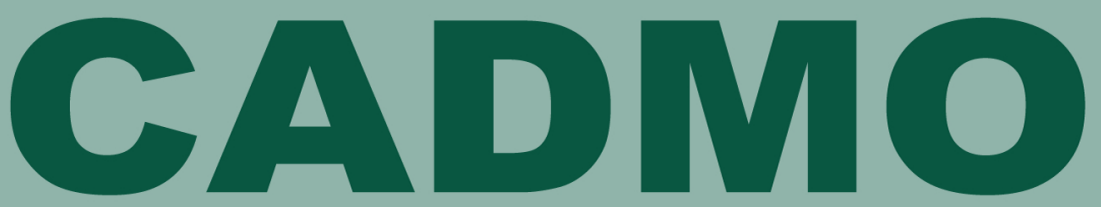

Revista de História Antiga

\section{Centro de História da Universidade de Lisboa}

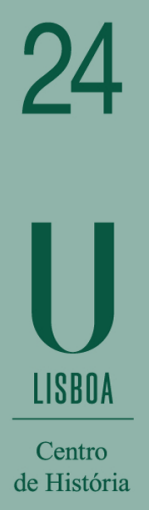

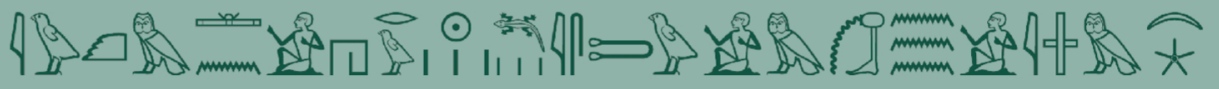

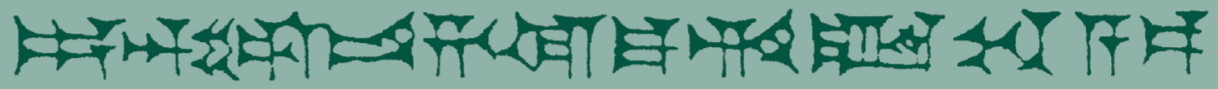
MHNIN AEI $\Delta$ E $\Theta E A ~ \Pi H \Lambda H I A \Delta E \Omega$ 
MARIO REGALI (2012), Il poeta e il demiurgo. Teoria e prassi della produzione letteraria nel Timeo e nel Crizia di Platone (International Plato Studies 30), Sankt Augustin, Academia Verlag, 213 pp. ISBN 978-3-89665-582-0 (€49.00).

Nas breves páginas que dedica à sua Introdução, Mario Regali mostra-se ciente do que de mais novo foi produzido no campo dos estudos platônicos. Nesse pequeno segmento, referências a pesquisas das últimas duas décadas dividem espaço com menções a pesquisas de nomes consagrados, entre os quais Pierre Hadot. Isso não se dá sem bons motivos; fundamentado nessas pesquisas, Regali pode recordar que a relação de Platão com a poesia vai além da «condenação, apenas aparente, do livro X da República» (p. 9) e que esta pode ser útil à polis quando adequada à investigação especulativa. É isso o que lhe permite determinar o escopo de sua pesquisa: "coniugare l'approccio critico mostrato dalle recenti ricerchi sulla poetica di Platone con i risultati raggiunti dalla esegesi sul Timeo e sul Crizia, per indagare [...] il contributo che [...] possono offrire alla concezione generale di produzione letteraria che è possibile atribuire a Platone (...) [e] verificare se tramite la prospettiva letteraria è possibile illuminare alcuni aspetti del Timeo e del Crizia» (p. 10).

É pela análise dos componentes literários dos relatos sobre o demiurgo e Atlântida que Regali realiza sua tarefa. No capítulo primeiro, ele analisa como Platão constrói seus textos a partir de alusões aos gêneros tradicionais da literatura: é assinalada, mediante o destaque de certos vocábulos, a presença da elegia simposial, do epos e do teatro, tal como de temas que evocam hinos e encômios salvos da condenação no livro décimo da República. No mesmo âmbito, Regali também se debruça sobre a construção e posição dos personagens de Sócrates, Timeu e Crítias, revelando como os traços de excelência de cada um busca fundamentar, sobre bases sólidas, «il tentativo di riforma della produzione letteraria della tradizione» (p. 176). Nesse aspecto, relacionar o que afirma Regali ao que Platão expõe na República é particularmente esclarecedor.

No segundo capítulo, o mais curto, o recurso de Platão aos gêneros literários da tradição se torna ainda mais claro. Regali analisa aqui o emprego da técnica épica do retardamento no Timeu e Crítias, mas não sem antes recordar como ela é utilizada por Homero, com especial ênfase no Catálogo das Naus. A partir do modelo homérico, pode notar-se como Platão se fundamenta no epos ao intercalar o prólogo 
sobre Atlântida, a narrativa - aparentemente deslocada - de Timeu sobre o demiurgo e o relato acerca da famosa ilha. Mas isso não é tudo: Platão, mostra-nos Regali, não emprega esse retardamento apenas nessa estrutura mais ampla, mas também no interior dos diálogos, nos quais detalhes são apresentados com vagueza, indo e voltando no tempo, para «dilatar o horizonte de espera» e ampliar o interesse do leitor pelo que está por vir.

Recorrendo novamente à autoridade das críticas recentes, o Capítulo III se inicia com o esclarecimento das várias nuances semânticas que o termo mimesis assume na obra de Platão. Com base nisso, é possível identificar certos traços da mimesis platônica no relato de ambos os títulos tratados, de modo particular no Timeu, por cujo personagem homônimo Platão também «construisce una trama di corrispondenze fra il narratore [...] [e] i suoi personaggi [...] che richiamano il rapporto mimetico fra poeta, pubblico e personaggio [...] che [Platone] considera il fulcro della produzione letteraria e della sua fruizione» ( $p$. 146). Emerge da cuidadosa análise de Regali a possibilidade de uma prática mimética positiva, de acordo com as normas de Sócrates e os resultados da investigação especulativa cara a Platão; com efeito, a construção de Timeu e Crítias se mostra em pleno acordo com as diretrizes estabelecidas em sua República ideal.

O Capítulo IV de II Poeta e il Demiurgo se volta especificamente à figura deste último; porém, embora retome os problemas encontrados por quem deseja definir qual é seu estatuto ontológico (inclusive no período da Academia antiga), opta por vê-lo sob a perspectiva literária. Regali recorda o papel do demiurgo como agente e, recorrendo tanto ao Fédon quanto à Poética de Aristóteles, relaciona a importância dessa agência para a sua classificação enquanto mythos. Também a partir de Aristóteles - e, dessa vez, ainda da República -, a relevância da praxis é destacada: inferior apenas à mimesis no contexto do debate sobre a produção literária, ela vincula o relato do Timeu às reflexões normativas estabelecidas por Platão no plano da teoria literária e demonstra o novo projeto literário a que aponta o filósofo.

O capítulo final retorna à esfera prática da relação entre a tradição literária e a produção platônica. Dessa vez, o autor toma como foco a figura do demiurgo, de modo particular seu nome e seu discurso aos deuses. Recorrendo à etimologia, «uno strumento della tradizione» (p. 175), demonstra como Platão retirou do proêmio dos Trabalhos e os Dias, de Hesíodo, a base do jogo etimológico relacionado ao nome 
do personagem. Além da etimologia, diz o autor, o discurso do próprio demiurgo evoca os Trabalhos: «la descrizione della potenza del demiurgo nel discorso agli dei è construita sul modelo dell'aretalogia di Zeus negli Erga tramite puntuali accordi nella dizione» (p. 178). O que faz Platão, em suma, é «attraverso l'etimologia [...] recupera[re] il contributo di Esiodo» e a ele conferir, para além da esfera etimológica, «una funzione ideologica nello sviluppo complessivo del cosmo richiamato dal Timeo al Crizia» (p. 175).

Il Poeta e il Demiurgo é, sem dúvida alguma, livro de enorme erudição: é escrito por um especialista para especialistas. Sua farta bibliografia e as numerosas notas de rodapé (666 no total) abrem uma série de veredas para quem deseja aprofundar suas pesquisas, ao mesmo tempo que apresentam panorama bastante completo daquilo que já foi dito sobre o assunto.

\section{Hugo Langone}

NICOLAS RICHER (2012), La Religion des Spartiates. Croyances et cultes dans l'Antiquité. (Histoire 113) Paris, Les Belles Lettres, 816 pp. ISBN 978-2-251-38113-8 (55.00€).

$\mathrm{Na}$ sequência dos seus trabalhos nas últimas décadas, Nicolas Richer apresenta uma obra sobre o assunto de que é académico de referência, o sistema religioso de Esparta. A monografia, contudo, não procura ser uma síntese regional orientada em torno dos conceitos fundamentais de culto, divindade e função desdobrados sobre a geografia da Lacónia de acordo com a documentação existente. Valoriza-se, essencialmente, a comunidade dos homoioi como eixo condutor do raciocínio monográfico e chave preferencial para a interpretação dos fenómenos religiosos historiáveis. Para Richer, são as relações permanentes entre o divino e as dinâmicas do grupo que organizam os elementos do rito, as narrativas mitológicas e estruturam as crenças. As respostas encontram-se na interpretação dos comportamentos, ritmos do quotidiano e da vivência de cada um enquanto espartano. A organização dos conteúdos obedece de uma forma clara a este programa de exegese, pelo que é evitada a exposição extensiva dos cultos do terrtório, sendo somente alguns escolhidos para estudos de caso quando enquadrados no nexo da proposta. 